CORRESPONDENCE

DOI: $10.1038 /$ s41467-018-03972-9

\title{
Anisotropy governs strain stiffening in nanotwinned-materials
}

\author{
Seyedeh Mohadeseh Taheri Mousavi ${ }^{1}$, Guijin Zou', Haofei Zhou ${ }^{1} \&$ Huajian Gao ${ }^{1}$
}

In their papers, $\mathrm{Li}$ et al. ${ }^{1,2}$ proposed an indentation strain stiffening mechanism to explain the experimentally reported ultra-high hardness of nanotwinned (nt-) $\mathrm{cBN}^{3}$ and nt-diamond ${ }^{4}$ at extremely small twin boundary (TB) thicknesses $(\lambda \leq 5 \mathrm{~nm})$. Here, however, we show that the strain stiffening mechanism proposed by these authors is not exclusive to nt-covalent-bonding materials and also exists in nt-metals which are known to exhibit a softening behavior below a critical twin spacing ${ }^{5,6}$.

To demonstrate this, molecular dynamics (MD) simulations were first conducted on a single crystalline $\mathrm{Cu}$ sample with dimensions of $40 \times 20 \times 56 \mathrm{~nm}^{3}$. Periodic boundary conditions were imposed at the boundaries of the sample. The embedded atom method potential for $\mathrm{Cu}$ was adopted to describe the interatomic interactions ${ }^{7}$, and the Nose-Hoover thermostat was used to maintain an NPT ensemble. The time step is set at $1 \mathrm{fs}$. The sample was relaxed at $1 \mathrm{~K}$ for $200 \mathrm{ps}$. A total shear strain of 90\% was applied along the (111)[112] (hard shearing) and (111) $[11 \overline{2}]$ (weak shearing) directions at a constant strain rate of $10^{9} \mathrm{~s}$ ${ }^{-1}$. The simulated stress-strain responses displayed in the left inset of Fig. 1 shows that continuous loading along the weak direction causes all atomic layers to be transformed into the hard direction, and the sample exhibits strain stiffening.

Next, similar MD simulations were performed on nt-Cu samples, with the same dimensions of $40 \times 21 \times 50 \mathrm{~nm}^{3}$, containing TBs with thicknesses $\lambda=0.63 \mathrm{~nm}, 0.83 \mathrm{~nm}, 1.25 \mathrm{~nm}$, and $2.54 \mathrm{~nm}$. After 200 ps relaxation, the samples were subjected to both shear and compression loading with ratio fixed at a constant value of $\tan \left(68^{\circ}\right)$, which is identical to the loading method applied in the original paper by Li et al. ${ }^{1,2}$ (see the right inset of Fig. 1). The simulated stress-strain curves in Fig. 1 for nt-Cu exhibit peak strengths which are insensitive to the TB spacing. The stress drops on the curves are caused by the movement of partial dislocations on TBs leading to TB migrations. The saw-tooth pattern continues until the nt-samples become twin-free and the strain stiffening takes place. The slope of the strain stiffening part of the curves is equivalent for all the samples as they share an identical twin-free single crystalline structure. It is noteworthy that the model in Fig. 1, which is identical to that used in refs. ${ }^{1}$ and ${ }^{2}$, cannot capture the TB-thickness dependence of strength as no grain boundaries have been considered.

The above simulations indicate that the strain stiffening mechanism proposed by $\mathrm{Li}$ et al. ${ }^{1,2}$ is not limited to nt-covalent bonding ceramics and exists also in nt-metals. Since it is known that nt-Cu exhibits softening behavior below a critical TB spacing ${ }^{5,6}$, this finding places significant doubt on the validity of the model of $\mathrm{Li}$ et al. ${ }^{1,2}$ in explaining the observed stiffening behaviors of nt-CBN and nt-Diamond.

\footnotetext{
${ }^{1}$ School of Engineering, Brown University, Providence, RI 02912, USA. Correspondence and requests for materials should be addressed to H.G. (email: huajian_gao@brown.edu)
} 


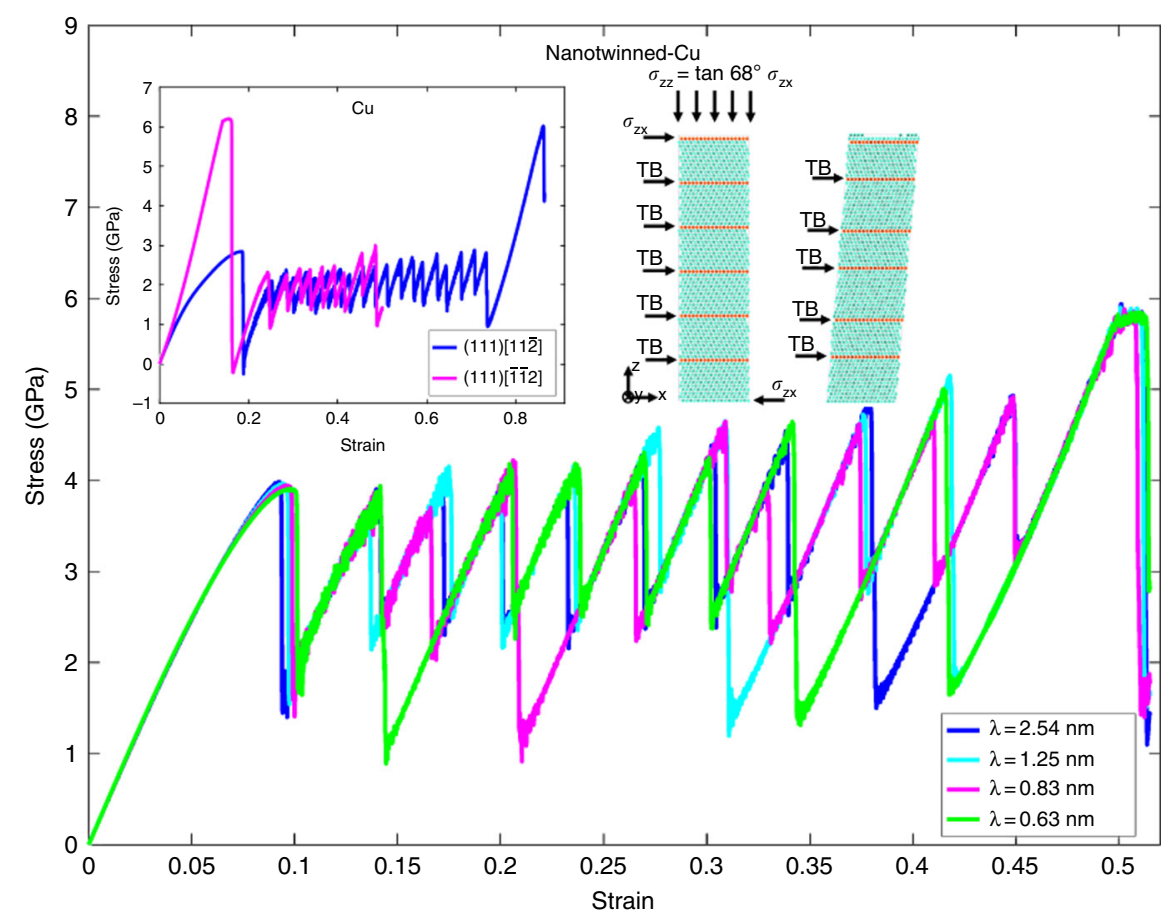

Fig. 1 Stress-strain curves of single crystalline and nanotwinned-Cu, and simulation set-ups for molecular dynamics simulations on nanotwinned samples. Simulated stress-strain relations of nanotwinned-Cu samples with twin thickness varying from $\lambda=0.63 \mathrm{~nm}$ to $2.54 \mathrm{~nm}$. The strength of the material and the tangent of the strain stiffening part are the same for samples with different twin boundary (TB) spacings. The simulation set-ups are shown in the right inset of the figure. The nantwinned-Cu super-cell is subjected to both shear and compressive loading similar to the Vickers indentation experiments. The compression to shear ratio is fixed at a constant value of $\tan \left(68^{\circ}\right)$. The left inset presents the stress-strain curves for a shear loading of a single crystalline $\mathrm{Cu}$ along hard (111)[112] and weak (111)[112] shear directions. Different slopes of the curves confirm the anisotropic behavior of Cu crystal similar to covalent-bonding materials

\section{Data availability}

All data generated and analyzed during this study are included in this published article.

Received: 11 October 2017 Accepted: 26 March 2018

Published online: 23 April 2018

\section{References}

1. Li, B., Sun, H. \& Chen, C. Large indentation strain-stiffening in nanotwinned cubic boron nitride. Nat. Commun. 5, 4965 (2014).

2. Li, B., Sun, H. \& Chen, C. Extreme mechanics of probing the ultimate strength of nanotwinned diamond. Phys. Rev. Lett. 117, 1-5 (2016).

3. Tian, Y. et al. Ultrahard nanotwinned cubic boron nitride. Nature 493, 385-388 (2013).

4. Huang, Q. et al. Nanotwinned diamond with unprecedented hardness and stability. Nature 510, 250-253 (2014).

5. Li, X., Wei, Y., Lu, L., Lu, K. \& Gao, H. Dislocation nucleation governed softening and maximum strength in nano-twinned metals. Nature $\mathbf{4 6 4}$, 877-880 (2010).

6. Lu, L., Chen, X., Huang, X. \& Lu, K. Revealing the maximum strength in nanotwinned copper. Science 323, 607-610 (2009).

7. Mishin, Y., Mehl, M. J., Papaconstantopoulos, D. A., Voter, A. F. \& Kress, J. D. Structural stability and lattice defects in copper: Ab initio, tight-binding, and embedded-atom calculations. Phys. Rev. B Condens. Matter 63, 2241061-22410616 (2001).

\section{Acknowledgements}

The authors acknowledge financial support from Swiss National Science Foundation through Grant P2ELP2_162144 (to S.M.T.M.) and National Science Foundation through grant DMR-1709318 (to G.J.Z., H.F.Z. and H.J.G.). The reported simulations were performed on resources provided by the Extreme Science and Engineering Discovery Environment (XSEDE) through Grant MS090046.

\section{Author contributions}

H.J.G. conceived and designed the project. S.M.T.M., G.J.Z. performed the molecular dynamics simulations. S.M.T.M., G.J.Z., H.F.Z. and H.J.G co-wrote the manuscript. All authors analyzed the results and contributed to the discussions.

\section{Additional information}

Competing interests: The authors declare no competing interests.

Reprints and permission information is available online at http://npg.nature.com/ reprintsandpermissions/

Publisher's note: Springer Nature remains neutral with regard to jurisdictional claims in published maps and institutional affiliations.

\begin{abstract}
cc) (i)
Open Access This article is licensed under a Creative Commons Attribution 4.0 International License, which permits use, sharing, adaptation, distribution and reproduction in any medium or format, as long as you give appropriate credit to the original author(s) and the source, provide a link to the Creative Commons license, and indicate if changes were made. The images or other third party material in this article are included in the article's Creative Commons license, unless indicated otherwise in a credit line to the material. If material is not included in the article's Creative Commons license and your intended use is not permitted by statutory regulation or exceeds the permitted use, you will need to obtain permission directly from the copyright holder. To view a copy of this license, visit http://creativecommons.org/ licenses/by/4.0/
\end{abstract}

(C) The Author(s) 2018 